\title{
A metabolic model of Lipomyces starkeyi for predicting lipogenesis potential from diverse low-cost substrates
}

Wei Zhou ${ }^{1 \dagger}$, Yanan Wang ${ }^{2 \dagger}$, Junlu Zhang ${ }^{1}$, Man Zhao ${ }^{1}$, Mou Tang ${ }^{1}$, Wenting Zhou ${ }^{1,3^{*}}$ and Zhiwei Gong ${ }^{1,3^{*}}$ (1)

\begin{abstract}
Background: Lipomyces starkeyi has been widely regarded as a promising oleaginous yeast with broad industrial application prospects because of its wide substrate spectrum, good adaption to fermentation inhibitors, excellent fatty acid composition for high-quality biodiesel, and negligible lipid remobilization. However, the currently low experimental lipid yield of $L$. starkeyi prohibits its commercial success. Metabolic model is extremely valuable to comprehend the complex biochemical processes and provide great guidance for strain modification to facilitate the lipid biosynthesis.

Results: A small-scale metabolic model of L. starkeyi NRRL Y-11557 was constructed based on the genome annotation information. The theoretical lipid yields of glucose, cellobiose, xylose, glycerol, and acetic acid were calculated according to the flux balance analysis (FBA). The optimal flux distribution of the lipid synthesis showed that pentose phosphate pathway (PPP) independently met the necessity of NADPH for lipid synthesis, resulting in the relatively low lipid yields. Several targets (NADP-dependent oxidoreductases) beneficial for oleaginicity of L. starkeyi with significantly higher theoretical lipid yields were compared and elucidated. The combined utilization of acetic acid and other carbon sources and a hypothetical reverse $\beta$-oxidation (RBO) pathway showed outstanding potential for improving the theoretical lipid yield.

Conclusions: The lipid biosynthesis potential of L. starkeyi can be significantly improved through appropriate modification of metabolic network, as well as combined utilization of carbon sources according to the metabolic model. The prediction and analysis provide valuable guidance to improve lipid production from various low-cost substrates.
\end{abstract}

Keywords: Lipomyces starkeyi, Metabolic model, Flux balance analysis, Triacylglycerol, Theoretical lipid yield

\section{Background}

Microbial lipid has garnered much attention recently as it can be served as promising feedstock for edible oils, functional polyunsaturated fatty acids, oleochemicals, and biodiesel [1]. Oleaginous species routinely

\footnotetext{
*Correspondence: gxuztw1986@wust.edu.cn; gongzhiwei@wust.edu.cn tWei Zhou and Yanan Wang contributed equally to this work ${ }^{1}$ School of Chemistry and Chemical Engineering, Wuhan University of Science and Technology, 947 Heping Road, Wuhan 430081, People's Republic of China

Full list of author information is available at the end of the article
}

accumulate large amount of intracellular lipid under nutritional restriction, especially nitrogen starvation [2]. Lipomyces starkeyi is an excellent lipid producer featuring wide substrate spectrum, good tolerance to fermentation inhibitors, excellent fatty acid composition of lipid for high-quality biodiesel, and negligible lipid remobilization. A variety of low-cost materials including lignocellulosic biomass, starch materials, biodiesel derived glycerol, volatile fatty acids, molasses, and sewage sludge have been applied for lipid production by $L$. starkeyi $[1,3]$. Especially, lignocellulosic hydrolysates have been directly utilized for lipid production without detoxification by $L$. 
starkeyi, which is of great significance for the commercial success $[4,5]$. L. starkeyi exhibits high robustness to the major lignocellulosic inhibitors including acetic acid, furfural, and 5-hydroxymethylfurfural (HMF) and these agents even could be metabolized by the yeast [5]. In addition, $L$. starkeyi scarcely consumes the cellular lipid although the nutrients are completely exhausted compared with other oleaginous species, which is beneficial for the preservation [6].

High effective genetic transformation system is crucial for improving the oleaginicity of oleaginous yeasts. Recently, a variety of genetic transformation methods including lithium acetate-mediated transformation, PEG-mediated spheroplast transformation, agrobacterium-mediated transformation, and electroporation transformation have been established for L. starkeyi [7-10]. A site-directed gene knockout strategy has been reported in L. starkeyi NRRL Y-11558 [11]. The development of synthetic biology approaches, coupled with the omics technologies [12-14], has continuously deepened the understanding of lipid metabolism of L. starkeyi [3].

Metabolic model has been widely used in many fields including industrial biotechnology $[15,16]$. The genome-scale metabolic model is convenient to predict biological capabilities and provide guidance for strain improvement. In recent years, a series of software have been developed to facilitate the automated and semiautomated construction of metabolic model [17]. Interestingly, genome-scale metabolic models of Yarrowia lipolytica, Rhodotorula toruloides, and Cutaneotrichosporon oleaginosus have been established to systematically analyze the lipid metabolism [18-20]. Small-scale metabolic model has been constructed in favor of some special purposes as the construction of the genome-scale metabolic model is very time-consuming and laborious. For example, Bommareddy and co-workers constructed a small-scale metabolic model of Rhodosporidium toruloides to evaluate the lipid production potential of several carbon sources [21]. A revised small-scale model containing 93 metabolites, 104 reactions, and 3 cell compartments was reconstructed by Castañeda and co-workers for more accurate prediction [22]. Tang and co-workers constructed a small-scale metabolic model of C. oleaginosum to evaluate the lipogenesis potential of chitinderived carbon sources [23].

Glucose, xylose, cellobiose, glycerol, and acetic acid originated from a variety of low-cost substrates can be metabolized for lipogenesis by L. starkeyi (Fig. 1). However, the experimental lipid yields were merely ranging from 0.08 to $0.18 \mathrm{~g} / \mathrm{g}$ as summarized in Table 1 [4, 24-32]. In this study, a small-scale metabolic model of $L$. starkey $i$ NRRL Y-11557 was constructed based on the genome annotation information. Flux balance analysis (FBA) was performed to calculate the theoretical lipid yields of a variety of carbon sources originated from low-cost substrates. Several targets (NADP-dependent oxidoreductases) were evaluated for improving the potential of lipid biosynthesis in L. starkeyi. The strategy of combined utilization of carbon sources mixture was investigated for improving the theoretical lipid yield. In addition, a hypothetical reverse $\beta$-oxidation (RBO) pathway was added to the model to estimate the lipid synthesis potential. This study provides valuable guidance and promising strategy to significantly improve lipid accumulation capacity from low-cost substrates.

\section{Results and discussion \\ Construction of the small-scale metabolic model of $L$. starkeyi}

All the reactions and metabolites in the small-scale metabolic model of $L$. starkeyi are summarized in the Additional file 1: Tables S1 and S2, respectively. The visualization of the metabolic map of $L$. starkeyi is depicted in Fig. 2. This model contained 112 metabolites, 123 reactions and 3 cell compartments including extracellular, cytoplasm, and mitochondria. The metabolic pathways included glycolysis, pentose phosphate pathway (PPP), tricarboxylic acid cycle (TCA), glyoxylate cycle, pyruvate dehydrogenase bypass, fatty acid (FA) synthesis pathway, and glycerolipid metabolism. The model involved in 13 exchange reactions and 31 transport reactions. The biomass reaction was used to analyze whether the metabolic model could normally generate biomass using a specific substrate. The model included the metabolism of 5 carbon sources including glucose, cellobiose, xylose, glycerol, and acetic acid. The $\mathrm{P} / \mathrm{O}$ ratios of the mitochondrial $\mathrm{NADH}$, mitochondrial FADH2, and cytoplasmic NADH were $2.5,1.5$, and 1.5 , respectively.

\section{Prediction of lipid production potential from different carbon sources}

The theoretical lipid yields of glucose, cellobiose, xylose, glycerol, and acetic acid by $L$. starkeyi were calculated and the results are shown in Table 2. The optimal flux distribution for lipid production from glucose is shown in Fig. 3a. It was clear that the FA and triacylglycerol (TAG) synthesis pathways were very active, while the TCA cycle were severely stagnant (Fig. 3a). This phenomenon was in line with the transcriptome analysis result reported by Pomraning and co-workers [13].

It should be noted that abundant $\mathrm{NADPH}$ is required for the FA synthesis. Generally, NADPH for FA synthesis is routinely supplied by the PPP and malic enzyme (ME) in oleaginous species [33]. However, NADPH originated from PPP meant carbon loss, which was undoubtedly detrimental to the lipid accumulation. Ratledge reported 


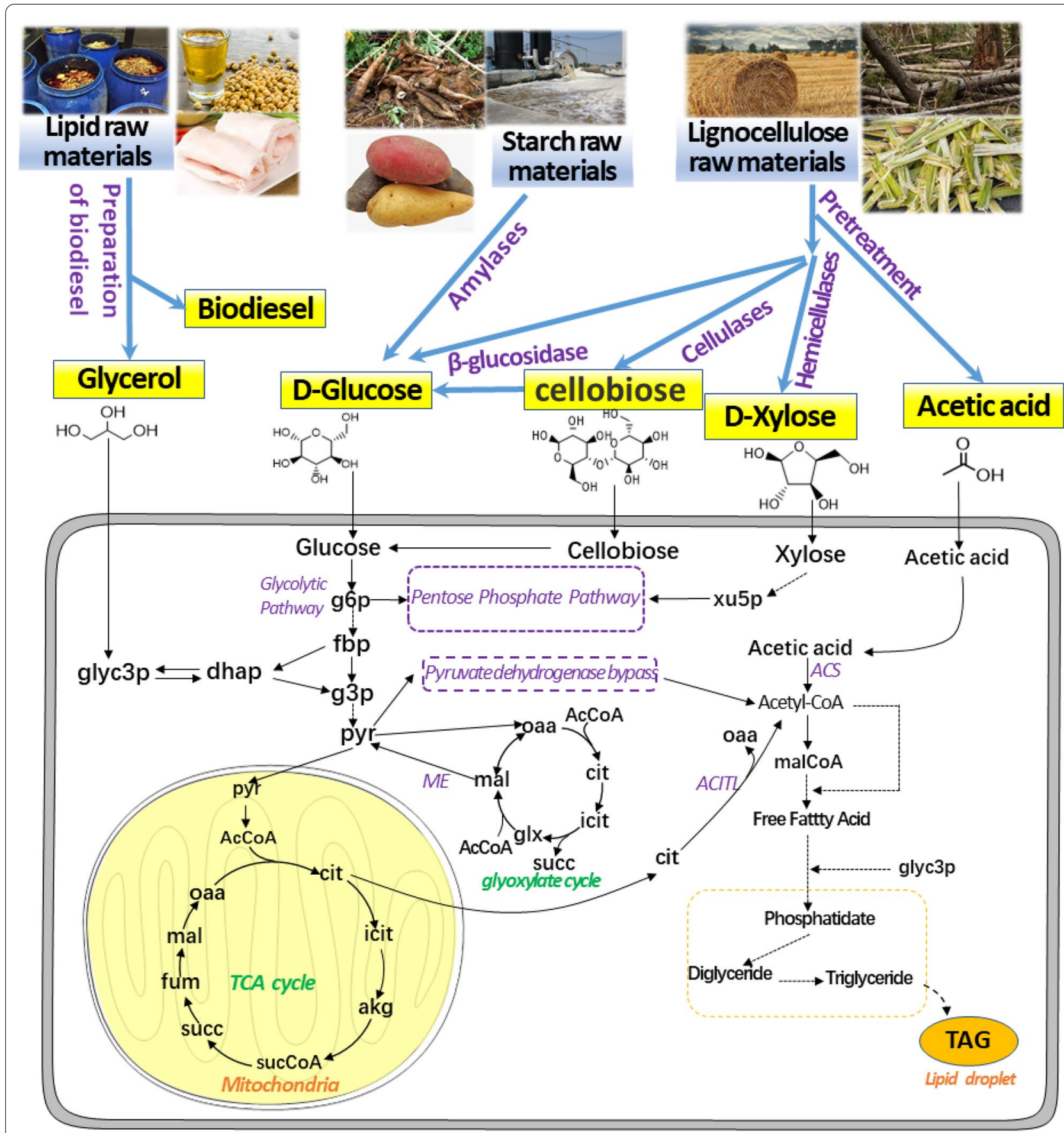

Fig. 1 The metabolic pathways of lipid biosynthesis by L. starkeyi from a variety of carbon sources originated from diverse low-cost substrates

that the theoretical lipid yield of glucose was $0.316 \mathrm{~g} / \mathrm{g}$ when both PPP and ME could serve as the suppliers of $\mathrm{NADPH}$, while the yield was merely $0.276 \mathrm{~g} / \mathrm{g}$ when PPP was the sole NADPH provider [33]. The ME in L. starkeyi AS 2.1560 was defined as NAD-dependent as described by Tang and co-workers [34]. The amino acid sequence of ME (ODQ72042) in L. starkeyi NRRL Y-11557 was virtually identical to that of $L$. starkeyi AS 2.1560. Thus, the $\mathrm{ME}$ in the model was recognized as NAD-dependent (ME1).

The theoretical lipid yields were merely $0.273,0.287$, 0.245 , and 0.267 , respectively, when glucose, cellobiose, xylose, or glycerol was the sole carbon source based on the model (Table 2). Among them, the yield on glucose 
Table 1 Lipid production from a variety of carbon sources by L. starkeyi

\begin{tabular}{|c|c|c|c|c|c|c|}
\hline Strain number & Substrates & $\begin{array}{l}\text { Culture } \\
\text { Mode }\end{array}$ & $\begin{array}{l}\text { Biomass } \\
(g / L)\end{array}$ & $\begin{array}{l}\text { Lipid content } \\
(\%, w / w)\end{array}$ & $\begin{array}{l}\text { Lipid yield } \\
(\mathrm{g} / \mathrm{g})\end{array}$ & References \\
\hline CBS 1807 & Glucose & $F B$ & 13.30 & 60.47 & 0.11 & [4] \\
\hline \multirow[t]{2}{*}{ DSM 70,295 } & Glucose & SF & 9.4 & 68 & ND & [24] \\
\hline & Sewage sludge & SF & 9.27 & 35.6 & ND & \\
\hline \multirow[t]{2}{*}{ NRRL Y-11557 } & Glucose & SF & 8.7 & 30 & 0.1 & [25] \\
\hline & Potato starch & B & 11.7 & 40.3 & 0.16 & \\
\hline \multirow[t]{2}{*}{ CBS 1807} & Glucose, fructose, sucrose & SF & 12.28 & 47.3 & 0.13 & [26] \\
\hline & Sweet sorghum juice & SF & 21.69 & 29.5 & 0.08 & \\
\hline NRRL Y-11557 & Raw glycerol & SF & 5.74 & 50.49 & 0.13 & [27] \\
\hline \multirow[t]{2}{*}{ NRRL Y-11557 } & Glucose & SF & 18.28 & 54.85 & 0.17 & {$[28]$} \\
\hline & Corn stover hydrolysate & SF & 24.63 & 38.07 & 0.14 & \\
\hline ATCC 58,680 & Glucose and xylose & SF & 9.43 & 56 & 0.18 & [29] \\
\hline \multirow[t]{3}{*}{ CBS 1807} & Glucose & SF & 18.71 & 28.9 & ND & {$[30]$} \\
\hline & Xylose & SF & 12.28 & 77.5 & ND & \\
\hline & Cellobiose & SF & 11.73 & 35.6 & ND & \\
\hline NRRL Y-11557 & Glucose & B & 5 & 46 & 0.177 & [31] \\
\hline DSM 70,295 & Crude glycerol & $F B$ & 32.7 & 55.9 & 0.15 & [32] \\
\hline
\end{tabular}

SF: shake flask, B: bioreactor, FB: fed-batch

ND: no data reported

was in agreement with the calculation result obtained by Ratledge [33]. The PPP was the unique supplier of $\mathrm{NADPH}$. Indeed, the NADPH required for FA synthesis by $L$. starkeyi was majorly provided by PPP according to the $\mathrm{C}^{13}$ metabolic flux analysis using $\mathrm{C}^{13}$-labeled glycerol as substrate [14]. The NADH generated during the metabolic process from glucose to acetyl-CoA was excessive and could not be used for FA synthesis according to the flux distribution analysis. The redundant NADH was eventually channeled into oxidative phosphorylation to produce ATP, which led to an excess of ATP. On the other hand, glucose was partially shunted to PPP to produce NADPH as large amount of NADPH was required for the FA biosynthesis, which resulted in a lower theoretical lipid yield. Similar situations occurred when xylose, glycerol, and cellobiose were used as substrates. It was probably one of the major reasons why relatively low experimental lipid yields were obtained (Table 1).

The theoretical lipid yield was merely $0.245 \mathrm{~g} / \mathrm{g}$ for acetic acid. Acetic acid was converted to acetyl-CoA by the acetyl-CoA synthase (ACS) before participating in cell metabolism $[35,36]$. The acetylation of acetic acid needs the participation of ATP, resulting in a relatively high demand for ATP in acetic acid metabolism. As shown in Table 3, acetic acid was inferior to glucose for providing NADH and ATP, which led to more acetic acid consumption to meet the requirement. As shown in Table 2, up to $37.14 \%$ of acetic acid was consumed through TCA cycle. Therefore, acetic acid was not an excellent building block for lipid production.

The lowest theoretical lipid yield was observed when xylose was used as substrate. It was because that xylose reductase needed one molecule of NADPH, which led to a greater demand for NADPH and more xylose channeling into PPP with an overall carbon loss of $30.57 \%$ (Table 2). This part of xylose was completely consumed to provide NADPH instead of conversion to acetyl-CoA as a precursor for FA synthesis. The more xylose was shunted to PPP, the less acetyl-CoA generated, resulting in a decrease in the theoretical lipid yield. Notably, when glucose, cellobiose, xylose, and glycerol were used as substrates, acetyl-CoA was always provided by pyruvate dehydrogenase bypass instead of ATP-citrate lyase (ACITL) to consume the redundant ATP as mentioned above.

\section{Prediction of potential targets for NADPH supply to enhance lipid production}

As mentioned above, the redundancy of NADH is one of the major issues against the theoretical lipid yield. Converting the redundant NADH to NADPH has great potential to reduce the carbon loss and enhance the theoretical lipid yield. Here, some modifications for enriching the supply of NADPH were evaluated in the metabolic model and the results are summarized in Table 2.

When glucose was used as substrate, the NADH generation was majorly referring to glyceraldehyde-3-phosphate 


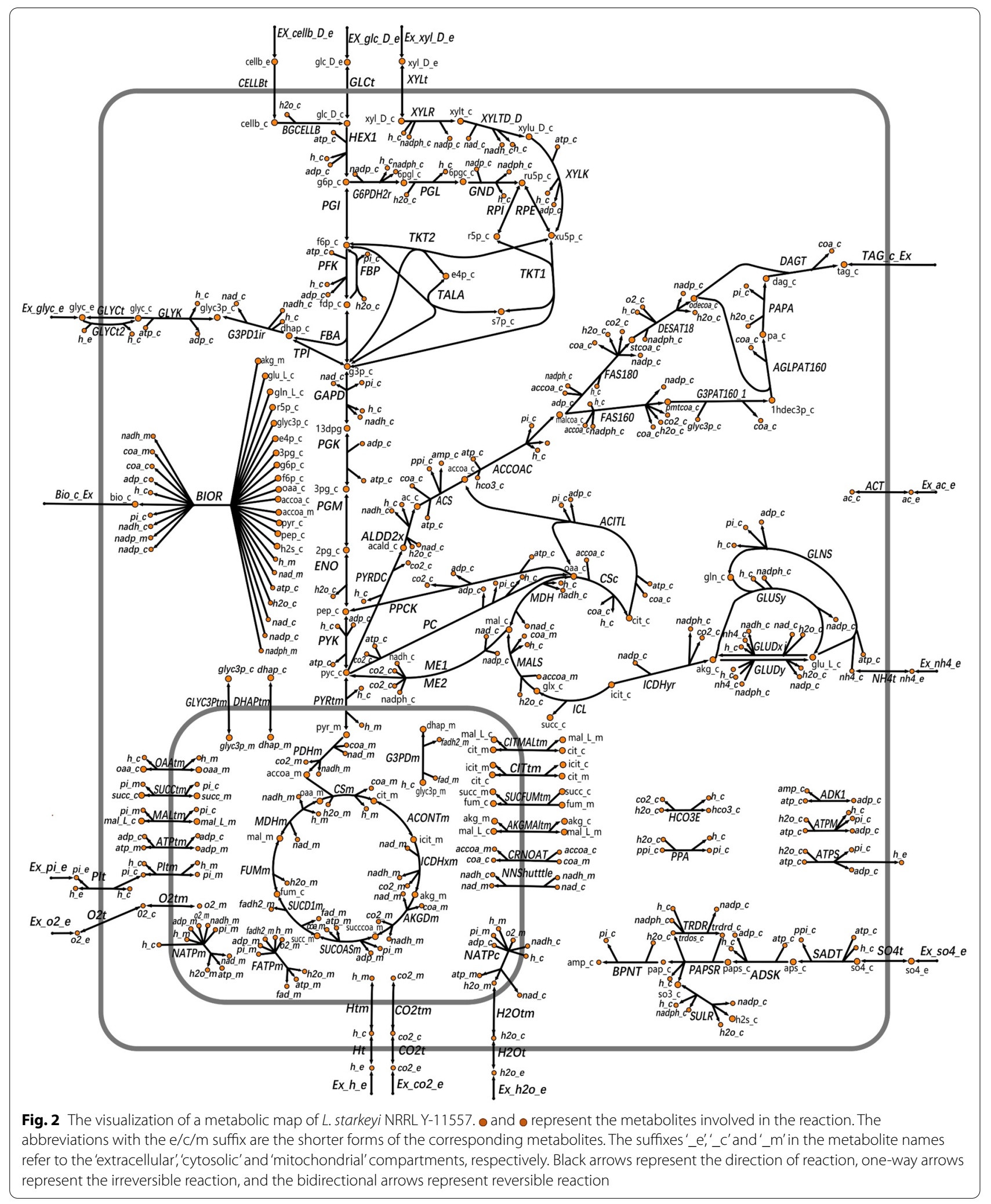




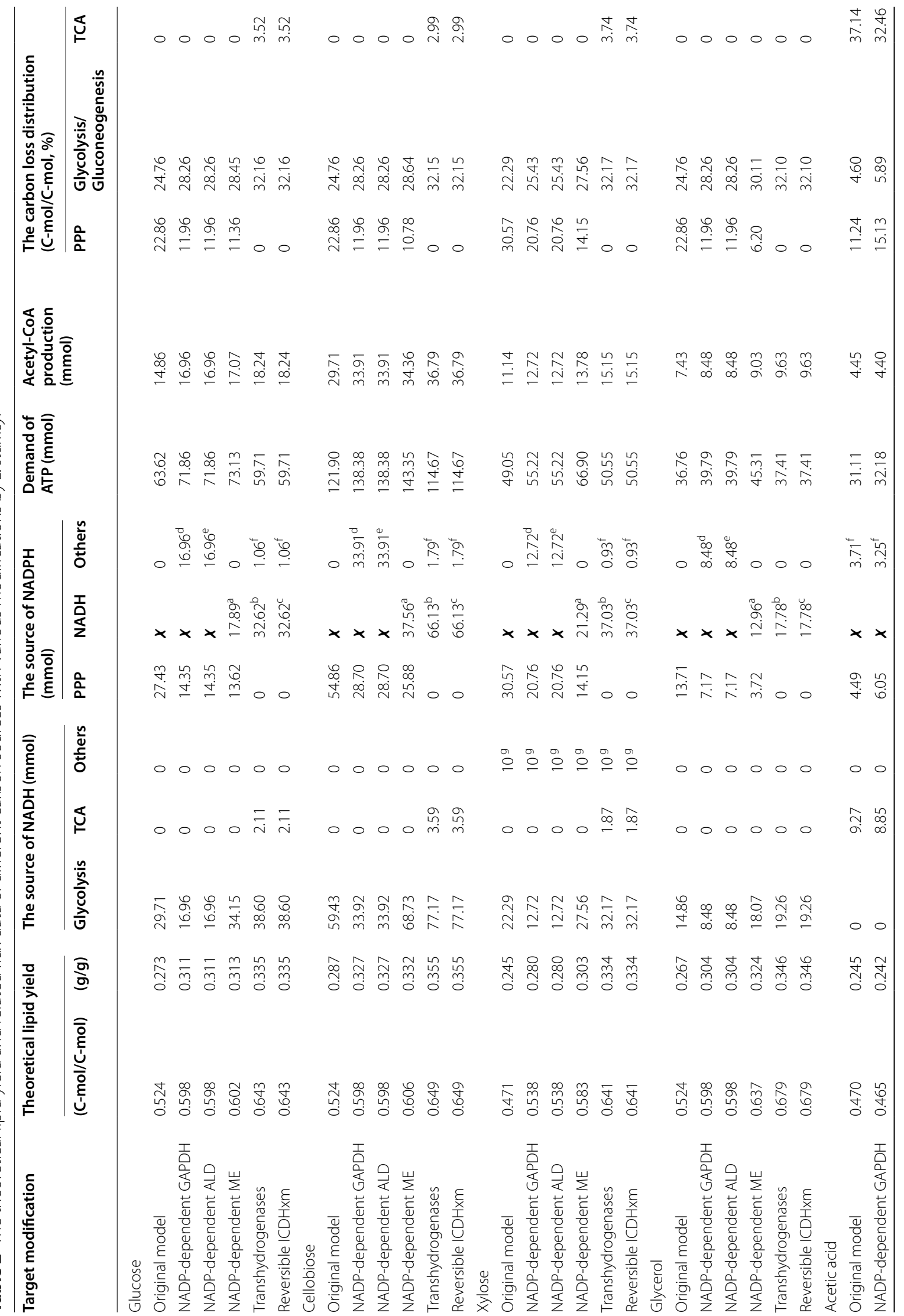




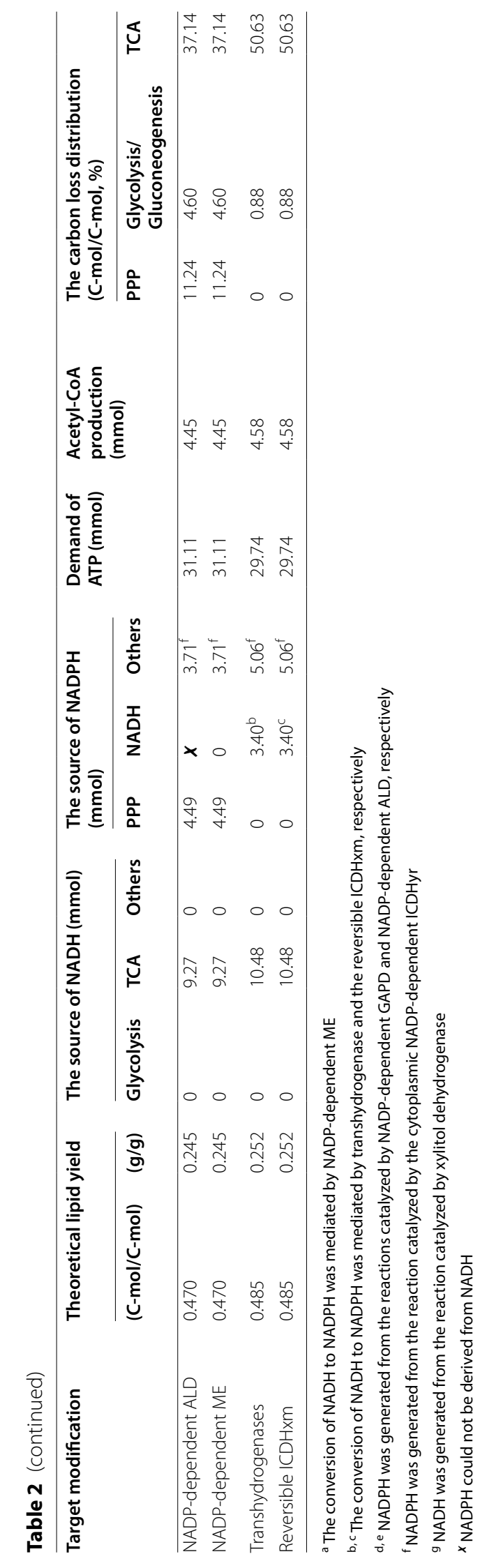




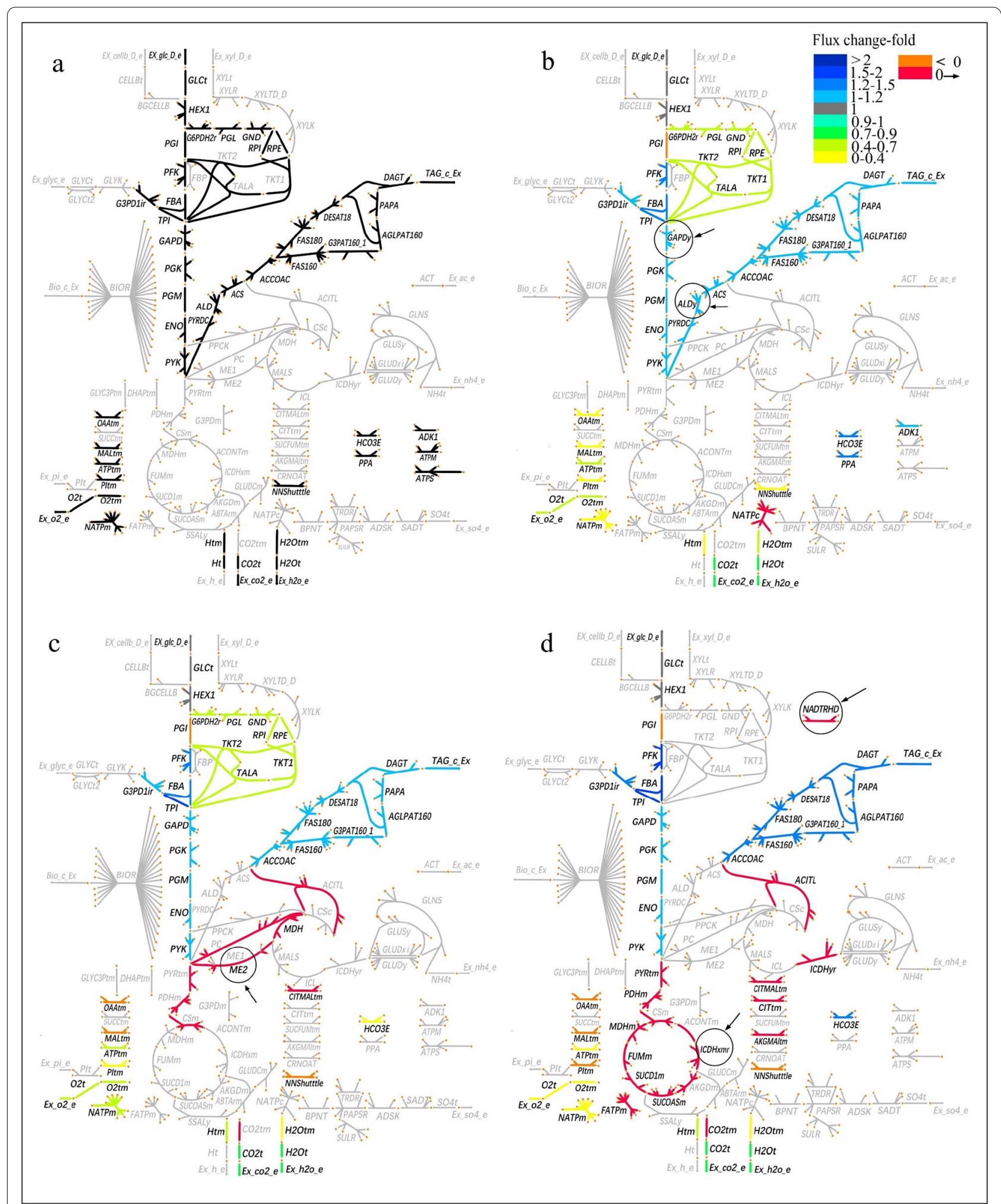

Fig. 3 Optimum flux distribution of TAG synthesis from glucose under various modifications. a Original model, b GAPD or ALD was replaced by the NADP-dependent isoenzymes $\mathbf{c}$ addition of ME2, $\mathbf{d}$ addition of NADTRHD or ICDHxmr. Flux fold-change refers to the ratio of the flux of the modified model to the original model. Different colors indicate different flux change-fold. "<0" means the reaction direction is opposite to the corresponding reaction in the original model, " $0 \rightarrow$ " means that the reaction with a flux of 0 in the original model has flux after modification. The relevant modifications are marked with circles 
dehydrogenase (GAPD) and aldehyde dehydrogenase (ALD) (Fig. 3a). The theoretical lipid yield was analyzed when either GAPD or ALD in the model was replaced by the NADP-dependent isoenzymes (GAPDy and ALDy). Specifically, the flux for glycolysis and FA biosynthesis were significantly increased when glucose was used as substrate (Fig. 3b vs Fig. 3a). The reaction catalyzed by GAPDy or ALDy could provide $54.17 \%$ of the required NADPH, which resulted in the proportion of glucose flowing to PPP decreasing from $22.86 \%$ to $11.96 \%$ and a significant decline of carbon loss (Table 2 and Fig. 3b). The theoretical lipid yield increased significantly from $0.273 \mathrm{~g} / \mathrm{g}$ to $0.311 \mathrm{~g} / \mathrm{g}$. However, $20.76 \%$ of xylose remained channeling into PPP despite the modification, leading to a significantly lower lipid yield of $0.280 \mathrm{~g} / \mathrm{g}$.

$\mathrm{NADH}$ can be changed to NADPH through a transhydrogenase cycle involving in pyruvate decarboxylase, malate dehydrogenase and NADP-dependent malic enzyme (ME2) [33]. Thus, ME2 was introduced into the metabolic model and the theoretical lipid yield was recalculated. The theoretical lipid yields of glucose, cellobiose, xylose, and glycerol, increased by $14.7 \%, 15.7 \%$, $23.7 \%$, and $21.3 \%$, respectively (Table 2 ). As shown in Table 2, $56.78 \%$ of the required NADPH was provided by ME2 when glucose was used as substrate. Similarly, the flux for glycolysis and FA biosynthesis were significantly increased with a sharp decline of the flux of PPP (Fig. 3c vs Fig. 3a). Specifically, the proportion of glucose channeling into PPP decreased from $22.86 \%$ to $11.36 \%$, and the theoretical lipid yield increased from $0.273 \mathrm{~g} / \mathrm{g}$ to $0.313 \mathrm{~g} / \mathrm{g}$ concurrently (Table 2 ). It was worth noting that when glycerol was used as the substrate, the enhancement in the theoretical lipid yield was the most significant. The proportion of glycerol flowing to PPP decreased from $22.86 \%$ to $6.20 \%$, and theoretical lipid yield increased from $0.267 \mathrm{~g} / \mathrm{g}$ to $0.324 \mathrm{~g} / \mathrm{g}$. It was because extra FADH2 was produced during the metabolism from glycerol to acetyl-CoA, which meant that more NADPH could be produced through ME2. The overexpression of ME2 in oleaginous fungus Mucor circinelloides resulted in a 2.5-fold increase in lipid content [37]. When the ME2 gene originated from M. circinelloides was expressed into Rhodotorula glutinis, the lipid content was increased significantly from 19 to $39 \%$ [38]. It was indicated that when ME2 can be introduced into L. starkeyi, it should have positive effect on lipid production.

The ME2-mediated NADPH production necessitates the consumption of ATP, which limits the theoretical lipid yield to a certain extent (Table 2). Here, NAD-dependent transhydrogenase (NADTRHD), changing NADH to NADPH directly without the necessity of ATP, was introduced into the metabolic model. An alternative approach to provide NADPH is reversing the direction of the mitochondrial NAD-dependent isocitrate dehydrogenase (ICDHxm) proposed by Ratledge [33]. NADH can be changed to NADPH without ATP consumption by a reversible NAD-dependent isocitrate dehydrogenase (ICDHxmr) and cytoplasmic NADP-dependent isocitrate dehydrogenase (ICDHyr). The introduction of ICDHxmr or NADTRHD has identical positive effect and the theoretical lipid yield of glucose reached as high as $0.335 \mathrm{~g} / \mathrm{g}$ (Table 2). The optimum flux distribution for TAG production is depicted in Fig. 3d. It was clear that no glucose was channeled into PPP, indicating that NADPH was no longer provided by PPP. Instead, part of acetyl-CoA was channeled into TCA cycle to provide NADH changing to NADPH (Fig. 3d). The NADPH required for lipid synthesis was predominantly derived from NADH. Interestingly, when glycerol was used as sole carbon source, the theoretical lipid yield reached a higher value of $0.346 \mathrm{~g} / \mathrm{g}$. It was because that the NADH generated from glycerol to acetyl-CoA metabolism was sufficient. Acetyl-CoA was not necessary to be consumed to provide NADH. The carbon loss was merely involved in glycolysis (Table 2). Interestingly, the theoretical lipid yield of xylose was significantly increased to $0.334 \mathrm{~g} / \mathrm{g}$ after the modifications, which was comparable to that of glucose (Table 2). The NADPH required by xylose reductase could be provided by NADH generated by xylitol dehydrogenase by the modifications.

It should be noted that all the modifications mentioned above exerted no significantly positive effects on the theoretical lipid yield when acetic acid was used as substrate. There was no redundant NADH because the metabolic process from acetic acid to acetyl-CoA did not produce $\mathrm{NADH}$ concurrently. Moreover, acetic acid was acetylated by ACS without involving in glycolysis and pyruvate dehydrogenase bypass pathways. Thus, ME2, GAPDy or ALDy not produce a marked effect on the theoretical lipid yield. On the other hand, the metabolic process from acetyl-CoA to PPP underwent gluconeogenesis, which resulting in greater carbon loss. The introduction of NADTRHD or ICDHxmr could slightly increase the theoretical lipid yield of acetic acid, as acetyl-CoA can be channeled into TCA cycle to produce NADH.

\section{Prediction of lipid production by combined utilization of different carbon sources}

Glucose and xylose are the two major monomeric sugars in the lignocellulosic hydrolysates. In addition, cellobiose and acetic acid are routinely co-present. Interestingly, combined utilization of carbon sources mixtures has been widely investigated for lipid production by $L$. starkeyi $[4,5,26,29,39-42]$. Most microorganisms prefer glucose over other monomeric sugars due to glucose catabolite repression. Sequential consumption of 
Table 3 Maximal yields of ATP, NADH, and acetyl-CoA from glucose and acetic acid

\begin{tabular}{llll}
\hline Carbon source & $\begin{array}{l}\text { ATP } \\
(\mathbf{m o l} / \mathrm{C}-\mathrm{mol})\end{array}$ & $\begin{array}{l}\text { NADH } \\
(\mathbf{m o l} / \mathrm{C}-\mathrm{mol})\end{array}$ & $\begin{array}{l}\text { Acetyl-CoA } \\
(\mathrm{mol} / \mathrm{C}-\mathrm{mol})\end{array}$ \\
\hline Glucose & 5.33 & 1.96 & 0.33 \\
Acetic acid & 4.00 & 1.55 & 0.40 \\
\hline
\end{tabular}

mixed carbon sources will prohibit the optimization of metabolic flux to give the yield advantage. It was worth mentioning that some mixed carbon sources including xylose/acetic acid [4], glucose/xylose/acetic acid [5, 39], cellobiose/xylose [40], and glucose/mannose [42] could be assimilated simultaneously by $L$. starkeyi. In addition, some feasible strategies including genetic modification and directed evolution have been developed to circumvent the catabolite repression and realize simultaneously utilize of mixed carbon sources [43-45]. Interestingly, simultaneous utilization of glucose and xylose was also realized by carefully controlling glucose concentration and dilution rate in chemostat culture [46]. A variety of strategies can be selected to circumvent sequential utilization issues when model-verified substrates combination shows benefit for lipid biosynthesis. Thus, it is meaningful to assess the potential of combined utilization of different low-cost carbon sources for improving the lipid yield. Here, the combined utilization of different carbon sources was analyzed and the theoretical lipid yields were calculated based on the model. Glucose, glycerol, xylose, and cellobiose mixed in pairs could not significantly improve the theoretical lipid yield (data not shown). In addition, the theoretical lipid yields were virtually identical regardless of the mass ratios of xylose and cellobiose, which was in accordance with the results reported by Gong and co-workers [40].

Interestingly, the theoretical lipid yield could be significantly improved when acetic acid was co-present with other carbon sources including glucose, cellobiose, xylose, or glycerol (Table 4). Among them, the combined utilization of acetic acid and glycerol could achieve the highest theoretical lipid yield $(\mathrm{C}$-mol/C-mol). It was because one more molecule of FADH 2 could be produced in the metabolism of glycerol to acetyl-CoA compared with sugars including glucose, cellobiose, and xylose. For acetic acid/glucose mixture, the effect of the acetic acid proportion on the theoretical lipid yield was investigated and the results are shown in Fig. 4. The theoretical lipid yield was continuously increased as the increase of the relative $q_{\mathrm{s} \text {, acetic acid }}$ from zero to $30 \%$ (Table 5 and Fig. 4). The highest value reached $0.313 \mathrm{~g} / \mathrm{g}$ when the relative $q_{\mathrm{s}}$, acetic acid reached $30 \%$. In this case, acetic acid was totally channeled into acetyl-CoA as precursor for FA synthesis and the NADH produced from the metabolism of
Table 4 Prediction of the theoretical lipid yield by combined utilization of acetic acid and other carbon sources

\begin{tabular}{llll}
\hline Carbon source & $\begin{array}{l}\text { Relative } \boldsymbol{q}_{\mathbf{s},} \\
\text { acetic acid } \\
\text { (\%) }\end{array}$ & $\begin{array}{l}\text { Theoretical } \\
\text { lipid yield } \\
\text { (C-mol/C-mol) }\end{array}$ & $\begin{array}{l}\text { Theoretical } \\
\text { lipid yield } \\
(\mathbf{g} / \mathbf{g})\end{array}$ \\
\hline Acetic acid/glucose & 30 & 0.602 & 0.313 \\
Acetic acid/cellobiose & 35 & 0.593 & 0.325 \\
Acetic acid/xylose & 40 & 0.585 & 0.304 \\
Acetic acid/glycerol & 35 & 0.620 & 0.316 \\
\hline
\end{tabular}

glucose into acetyl-CoA met the requirement. The acetylation of acetic acid requires the consumption of ATP. The ATP was provided by the oxidative phosphorylation process, which was beneficial for alleviating the wastage of the excessive NADH. As shown in Table 5, the proportion of glucose flowing to PPP increased as the increase of acetic acid flux. The increase in the theoretical lipid yield at this stage was majorly due to the consumption of the redundant NADH via acetic acid metabolism and the increment of acetyl-CoA for FA synthesis.

The theoretical lipid yield was continuously decreased when the acetic acid proportion was exceeding 30\% (Fig. 4). The demand for ATP increased with the increase of acetic acid flux. The NADH generated via the metabolism of glucose to acetyl-CoA became inadequate. Acetyl-CoA began to be consumed through TCA cycle to provide NADH, which led to a continuously increase in carbon loss and decrease in theoretical lipid yield (Table 5). When the relative $q_{\mathrm{s} \text {, acetic acid }}$ exceeded $85.1 \%$, glucose was totally channeled into PPP to supply NADPH. However, the NADPH remained inadequate to support the FA synthesis. Part of the acetyl-CoA was

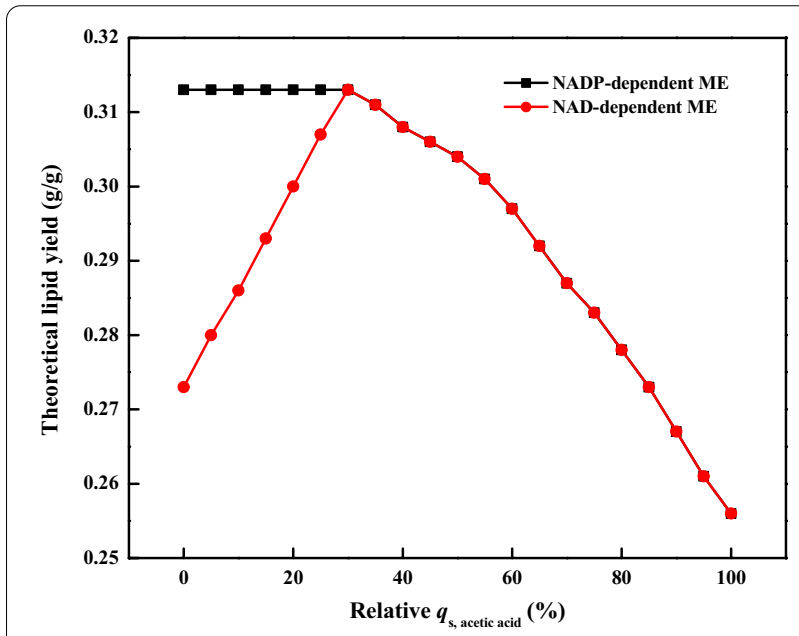

Fig. 4 The effect of the acetic acid and glucose co-utilization strategy on the theoretical lipid yield. The black and red lines represent NADP-dependent ME and NAD-dependent ME, respectively 
Table 5 Prediction of the theoretical lipid yield and related flux data by combined utilization of acetic acid and glucose

\begin{tabular}{|c|c|c|c|c|c|c|c|c|c|}
\hline \multirow{2}{*}{$\begin{array}{l}\text { Relative } \\
q_{\mathrm{s}, \text { acetic acid }} \\
(\%)\end{array}$} & \multirow{2}{*}{$\begin{array}{l}\text { Theoretical } \\
\text { lipid yield } \\
\text { (g/g) }\end{array}$} & \multirow[t]{2}{*}{$\begin{array}{l}\text { Demand of } \\
\text { ATP }(\mathrm{mmol})\end{array}$} & \multirow{2}{*}{$\begin{array}{l}\text { Acetyl-CoA } \\
\text { production } \\
\text { (mmol) }\end{array}$} & \multicolumn{3}{|c|}{$\begin{array}{l}\text { The proportion of the flux } \\
\text { distribution of glucose (\%) }\end{array}$} & \multicolumn{3}{|c|}{$\begin{array}{l}\text { The proportion of the flux } \\
\text { distribution of acetic acid (\%) }\end{array}$} \\
\hline & & & & PPP & Lipid precursors $^{\mathrm{a}}$ & TCA & PPP & Lipid precursors & TCA \\
\hline 0 & 0.273 & 63.62 & 14.86 & 22.86 & 77.14 & 0 & - & - & - \\
\hline 15 & 0.293 & 63.49 & 15.97 & 28.91 & 71.09 & 0 & 0 & 100 & 0 \\
\hline 30 & 0.313 & 55.25 & 17.10 & 37.48 & 62.32 & 0.21 & 0 & 100 & 0 \\
\hline 50 & 0.304 & 56.95 & 16.53 & 45.36 & 21.65 & 32.99 & 0 & 100 & 0 \\
\hline 70 & 0.287 & 64.18 & 15.65 & 60.53 & 10.04 & 29.43 & 0 & 74.55 & 25.45 \\
\hline 90 & 0.267 & 75.09 & 14.55 & 100 & 0 & 0 & 6.54 & 58.04 & 35.42 \\
\hline 100 & 0.256 & 84.05 & 13.92 & - & - & - & 17.79 & 49.95 & 32.25 \\
\hline
\end{tabular}

${ }^{a}:$ Lipid precursors were consisted of acetyl-CoA and glycerol

channeled into gluconeogenesis and PPP to produce $\mathrm{NADPH}$.

The metabolic flux and theoretical lipid yield were analyzed when ME2 was added into the model. As depicted in Fig. 4, the theoretical lipid yield could be maintained at a relatively high level when the relative $q_{\mathrm{s} \text {, acetic acid }}$ was lower than $30 \%$. Interestingly, the yields became identical when the relative $q_{\mathrm{s} \text {, acetic acid }}$ was higher than $30 \%$ regardless of the presence of ME2. In the presence of ME2, the transhydrogenase cycle could change the redundant $\mathrm{NADH}$ to NADPH for the FA synthesis, which led to the decrease in glucose channeling into PPP and the increase in lipid yield. There was redundant NADH in the metabolic network when the relative $q_{\mathrm{s} \text {, acetic acid }}$ was lower than $30 \%$. This part of NADH could be converted into NADPH through ME2, which reduced the flux of glucose flowing to PPP. The redundant NADH in the metabolic network gradually decreased as the acetic acid flux increased. Correspondingly, the flux of ME2 gradually decreased. The ME2 did not work when relative $q_{\mathrm{s} \text {, acetic }}$ acid was higher than $30 \%$ because there was no redundant NADH in the metabolic network.

Acetic acid was not an excellent carbon source when it was used as the sole carbon source. Interestingly, when acetic acid was used in combination with other carbon sources including glycerol, glucose, cellobiose, and xylose, the lipid production could be improved. Actually, acetic acid and sugars co-fermentation has been validated as a promising strategy for lipid production by some oleaginous species [36, 47, 48]. Acetic acid was reported to be assimilated simultaneously with glucose and xylose by L. starkeyi $[4,5,39]$. The $q_{\mathrm{s} \text {, acetic acid }}$ was reported slightly

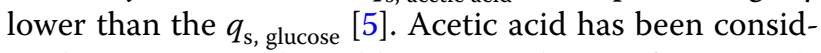
ered as a sustainable and low-cost substrate from a wide array of sources [49]. Especially, acetic acid is routinely co-present with lignocellulosic hydrolysates and can reach concentrations as high as $10 \mathrm{~g} / \mathrm{L}$ depending on the feedstock and the pretreatment method $[4,49]$. Thus, the combination utilization strategy will probably be a very promising strategy for lipid production.

\section{Prediction of lipid production by the RBO pathway}

Dellomonaco and co-workers proposed a novel RBO pathway to synthesize alcohols or carboxylic acids with various chain lengths [50]. This pathway can save large amount of ATP as the conversion of acetyl-CoA to malonyl-CoA was not a necessity. In addition, NADH is the majorly required coenzyme in the $\mathrm{RBO}$ route. There was no need to change the redundant NADH to NADPH for FA synthesis. Here, a hypothetical RBO pathway was introduced into the metabolic model to produce long-chain FA (C16:0 and C18:1). The hypothetical reactions (FAS160* and FAS180*) are described in Additional file 1: Table S1. The theoretical lipid yields of glucose, cellobiose, xylose, glycerol, and acetic acid were all significantly increased when the RBO pathway was introduced (Table 6). Interestingly, the theoretical lipid yields of glucose, cellobiose, and acetic acid were all achieved the maximal improvement among all the modification strategies (Table 6 vs Table 2). The effect of the RBO pathway on the optimal flux distribution of glucose is illustrated in Fig. 5. The FA was no longer produced through the FA synthesis pathway but through the RBO pathway when this pathway was introduced (Fig. 5). In addition, part of the acetyl-CoA was provided by pyruvate dehydrogenase bypass. The amount of ATP for lipid synthesis was reduced, and the NADH generated in the process from glucose to acetyl-CoA was sufficient to meet the requirement for lipid synthesis. Acetyl-CoA was no longer consumed through TCA cycle to provide NADH. The maximal lipid yield of glucose should be $0.679 \mathrm{C}$-mol/C-mol only taking the minimal carbon loss into account using TAG (16:0,18:1,18:1) as the target product. As depicted in Table 6, the theoretical lipid yields of glucose, cellobiose, and glycerol were infinitely approaching this 


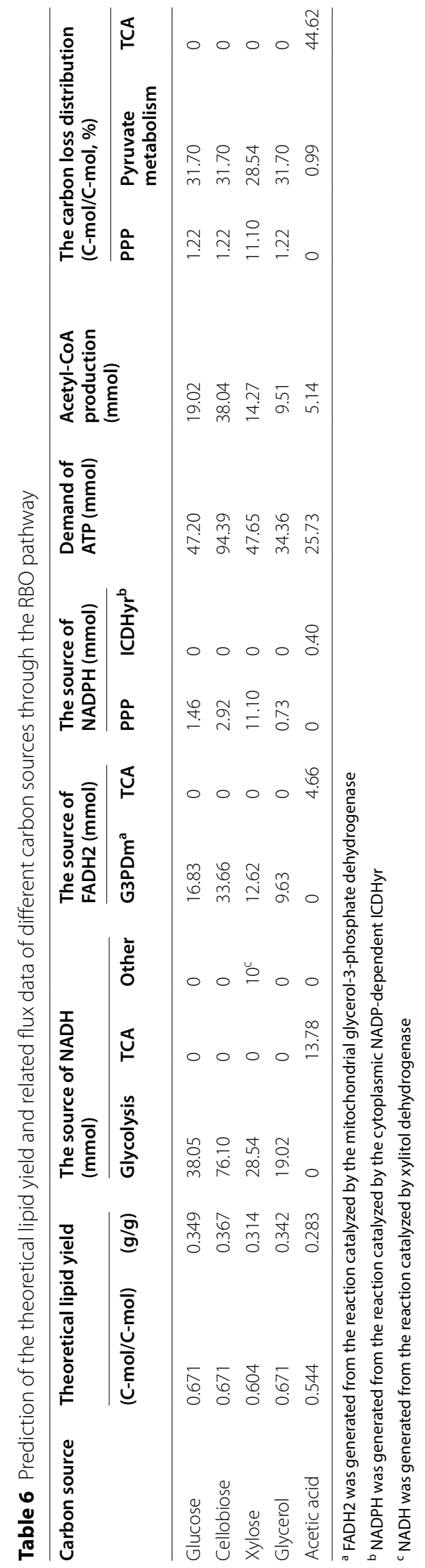




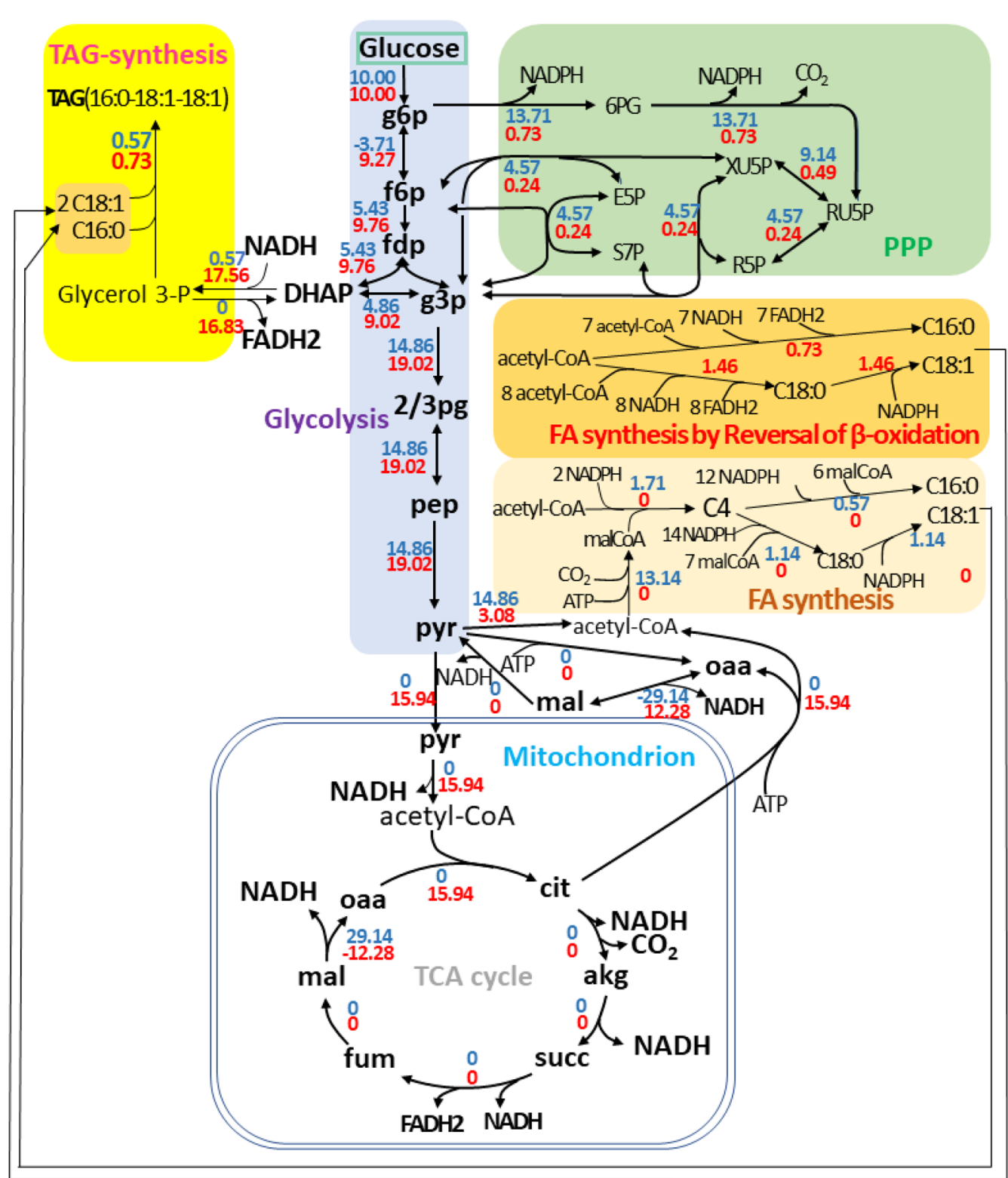

Fig. 5 Optimum flux distribution of TAG synthesis from glucose. The blue and red numbers represent the optimal flux distributions through the FA synthesis pathway and the RBO pathway, respectively

value, indicating the great potential of the RBO pathway for the FA production. It was worth noting that the enhancement was majorly due to the reduction of ATP requirement in the process of lipid synthesis. The theoretical lipid yield of xylose was merely $0.314 \mathrm{~g} / \mathrm{g}$, which was significantly lower than that of the modification of NADTRHD or ICDHxmr. It was because the RBO pathway caused severer carbon loss through PPP as the NADPH required for xylose metabolism could not be transformed from NADH (Table 6 vs Table 2).
At present, most of the experiments referring to the RBO pathway were carried out in prokaryotic cell such as Escherichia coli. The RBO pathway is in favor of short and medium-chain FA production because it is easy to control product lengths [50-52]. For example, Dellomonaco et al. reported that the production of n-butanol by E. coli through the RBO strategy reached $14 \mathrm{~g} / \mathrm{L}$ [50]. Recently, the production of medium-chain FA by E. coli via the RBO pathway reached $3.8 \mathrm{~g} / \mathrm{L}$ [52]. It was worth mentioning that the introduction of RBO pathway was 
successful in the eukaryote Saccharomyces cerevisiae. Lian et al. reported the production of $20 \mathrm{mg} / \mathrm{L} \mathrm{n}$-butanol through this strategy [53]. There was no report involving in the RBO strategy in the oleaginous species. The implementation of this novel strategy to improve the lipid yield should be a challenging task.

\section{Conclusions}

A small-scale metabolic model of L. starkeyi was successfully constructed for predicting the lipogenesis potential from diverse low-cost substrates. The theoretical lipid yields were relatively low according to the metabolic model. The redundant NADH generated could not be directly used for the synthesis of FA, while part of the carbon source was shunted to PPP to provide NADPH, which caused the decline in theoretical lipid yield. Some modifications were proposed in the model to effectively use the redundant NADH, reduce the carbon loss, and increase the theoretical lipid yield. Combined utilization of acetic acid and sugars/glycerol was a promising strategy to enhance the lipid accumulation potential. The theoretical lipid yield could be significantly improved through the RBO pathway, suggesting the great potential of this strategy to overproduce long-chain FA. In future, these strategies should be experimentally verified and a genome-scale metabolic model of $L$. starkeyi should be constructed for more accurate and comprehensive prediction.

\section{Methods}

\section{Strain}

L. starkeyi NRRL Y-11557 was used throughout the study. The complete genome sequence was published in 2016, and the GenBank entry number was GCA_001661325.1 [54]. The genome annotation information can be found on JGI MycoCosm. L. starkeyi NRRL Y-11557 is also numbered as NRRL Y-1388, ATCC 58,680, CBS 1807, DSM 70,925, IFO 1289, JCM 5995, etc., in different preservation centers [1].

\section{Construction of metabolic model}

Genome-scale metabolism models of iMM904 and yeast 8.3.5, as well as the small-scale metabolism models of $R$. toruloides and C. oleaginosum, were used as reference models for the construction of the small-scale metabolism model of $L$. starkeyi. All metabolites and reactions in the model refer to KEGG, BIGG and yeast 8.3.5. Subcellular localization of reactions referred to CELLO2GO and the visualization of metabolic model referred to Escher.
The gene information related to glycolysis, pyruvate metabolism, tricarboxylic acid cycle (TCA), pentose phosphate pathway (PPP), glyoxylate cycle, oxidative phosphorylation, fatty acid (FA) synthesis, and glycerolipid metabolism were obtained from JGI MycoCosm. Oleic acid (C18:1) and palmitic acid (C16:0) are routinely the predominant components in the fatty acid composition of L. starkeyi [4]. Therefore, TAG $(16: 0,18: 1,18: 1)$ was set as the target in the metabolic model. Since the biomass composition of L. starkeyi NRRL Y-11557 was not determined, the biomass response equation was quote directly $[22,23,55,56]$. The metabolic reactions of ammonia nitrogen, sulfate, glucose, cellobiose, xylose, glycerol, and acetic acid were added to the rough model. The exchange reactions and the transport reactions between mitochondria and cytoplasm were also added. The transport reactions refer to the genome annotation of $L$. starkeyi, yeast 8.3.5, iMM904, and the small-scale metabolic models of $R$. toruloides and C. oleaginosum [22, 23]. Through the system feasibility test, the transport reaction of corresponding metabolite was supplemented to fill the gap based on the blocked reaction. In addition, the spontaneous reactions and ATP maintenance reactions (ATPM) were supplemented to the rough model.

The non-growth associated maintenance (NGAM) was expressed by the ATPM, pseudo-reaction consuming ATP and representing wasted energy [22]. The theoretical lipid yield should be overestimated when the minimal flux of ATPM was not restricted. Thus, NGAM in the model was represented by setting the lower limit of ATPM to a minimum value based on a published model [22]. The minimal flux for ATPM was determined according to the following equation:

$$
V_{N G A M}=m_{S} \times y_{A T P / S},
$$

where $m_{S}$ is the maintenance coefficient, and the $y_{A T P / S}$ is the theoretical maximal ATP yield based on a specific substrate. $y_{A T P / S}$ was calculated by setting ATPM as the objective function based on the model. The $m_{S}$ coefficient of $L$. starkeyi was $30 \mathrm{mg}$ xylose/g cell mass/ $h$ according to the estimation by Anschau and coworkers [57].

\section{Model calibration}

The analysis of the model was carried out with the help of CellNetAnalyzer running on the MATLAB R2013a platform [58]. The system feasibility and redundancy were tested for the preliminary version of the metabolic network. If the results showed that the operation failed, searching the blocked reactions. Pay 
attention to the transport reaction between mitochondria and cytoplasm. If it remained unresolved, the entire metabolic model should be divided into several parts by adding the output of some metabolites. The flux optimization analysis was conducted to check if the system could be operated normally. The input flux of glucose, cellobiose, xylose, glycerol, or acetic acid was set at $10 \mathrm{mmol} / \mathrm{g} / \mathrm{h}$. FBA and flux optimization analysis were conducted to check if biomass and TAG could be synthesized normally.

\section{In silico analysis of the metabolic network}

The coefficients of the biomass reaction and the TAG exchange reaction were set at 0 and -1 , respectively, to ensure that the flux of TAG was maximized when the FBA was performed. To calculate the theoretical lipid yield of glucose, cellobiose, xylose, glycerol or acetic acid, the input flux of the specific carbon source was set at $10 \mathrm{mmol} / \mathrm{g} / \mathrm{h}$. The actual absorption rate of each carbon source was not considered. For the combination utilization of acetic acid and glucose, the total specific uptake rates $\left(q_{\mathrm{s} \text {, global }}\right)$ were always set to 1.8 $\mathrm{g}_{\text {substrate }} / \mathrm{g} / \mathrm{h}$, corresponding to $10 \mathrm{mmol}_{\text {glucose }} / \mathrm{g} / \mathrm{h}$. The relative specific acetic acid uptake rate $\left(q_{\mathrm{s}}\right.$, acetic acid $)$ was expressed as the proportion of $q_{\mathrm{s} \text {, acetic acid }}$ accounting for the $q_{\mathrm{s} \text {, global }}$. The effect of relative $q_{\mathrm{s} \text {, ace- }}$ tic acid ranging from zero to $100 \%$ on the yield advantage was estimated. The FBA was performed to obtain the optimal metabolic flux distribution for the synthesis of TAG. After conversion, the theoretical lipid yield corresponding to the input carbon source was obtained.

\begin{abstract}
Abbreviations
FA: Fatty acid; RBO: Reverse $\beta$-oxidation; PPP: Pentose phosphate pathway; FBA: Flux balance analysis; NRRL: Agricultural Research Service Culture Collection; TAG: Triacylglycerols; TCA: Tricarboxylic acid; ME: Malic enzyme; ME1: NAD-dependent malic enzyme; ME2: NADP-dependent malic enzyme; ACITL: ATP-citrate lyase; GAPD: Glyceraldehyde-3-phosphate dehydrogenase; GAPDy: NADP-dependent glyceraldehyde-3-phosphate dehydrogenase; ALD: Aldehyde dehydrogenase; ALDy: NADP-dependent aldehyde dehydrogenase; NADTRHD: NAD-dependent transhydrogenase; ICDHyr: NADP-dependent isocitrate dehydrogenase; ICDHxm: Mitochondrial NAD-dependent isocitrate dehydrogenase; ICDHxmr: Reversible NAD-dependent isocitrate dehydrogenase; FAS 160*: Fatty acid (16:0) synthesis reaction through RBO pathway; FAS 180*: Fatty acid (18:0) synthesis reaction through RBO pathway; ATPM: ATP maintenance reactions; NGAM: Non-growth associated maintenance.
\end{abstract}

\section{Supplementary Information}

The online version contains supplementary material available at https://doi. org/10.1186/s13068-021-01997-9.

Additional file 1: Table S1. Reactions in the small-scale metabolic model of L. starkeyi NRRL Y-11557. Table S2. Metabolites in the small-scale metabolic model of L. starkeyi NRRL Y-11557.
Acknowledgements

Not applicable.

\section{Authors' contributions}

WZ constructed the metabolic model and analyzed the results. YNW participated in the flux balance analysis and commented on the manuscript. JLZ, MZ and MT participated in the construction of the metabolic model. WTZ analyzed the results and drafted the manuscript. ZWG designed the study, coordinated the study and revised the manuscript. All authors approved the final manuscript.

\section{Funding}

This research was financially supported by the National Natural Science Foundation of China (51608400), the Fundamental Research Funds for the Central Public Welfare Research Institutes (ZZ13-YQ-085-C1), and the Fund from Key Laboratory of Hubei Province for Coal Conversion and New Carbon Materials (WKDM202108)

\section{Availability of data and materials}

All appropriate data for this study has been included in the manuscript.

\section{Declarations}

Ethics approval and consent to participate

Not applicable.

\section{Consent for publication}

All authors have given their consent for publication.

\section{Competing interests}

The authors declare that they have no competing interests.

\section{Author details}

${ }^{1}$ School of Chemistry and Chemical Engineering, Wuhan University of Science and Technology, 947 Heping Road, Wuhan 430081, People's Republic of China. ${ }^{2}$ State Key Laboratory Breeding Base of Dao-Di Herbs, National Resource Center for Chinese Materia Medica, China Academy of Chinese Medical Sciences, Beijing 100700, People's Republic of China. ${ }^{3}$ HuBei Province Key Laboratory of Coal Conversion and New Carbon Materials, Wuhan University of Science and Technology, Wuhan 430081, People's Republic of China.

Received: 16 April 2021 Accepted: 17 June 2021

Published online: 01 July 2021

References

1. Sutanto S, Zullaikah S, Tran-Nguyen PL, Ismadji S, Ju YH. Lipomyces starkeyi: Its current status as a potential oil producer. Fuel Process Technol. 2018:177:39-55.

2. Ratledge C, Cohen Z. Microbial and algal oils: Do they have a future for biodiesel or as commodity oils? Lipid Technol. 2008;20(7):155-60.

3. Takaku H, Matsuzawa T, Yaoi K, Yamazaki H. Lipid metabolism of the oleaginous yeast Lipomyces starkeyi. Appl Microbiol Biot. 2020:104(14):6141-8.

4. Brandenburg J, Blomqvist J, Pickova J, Bonturi N, Sandgren M, Passoth V. Lipid production from hemicellulose with Lipomyces starkeyi in a $\mathrm{pH}$ regulated fed-batch cultivation. Yeast. 2016;33(8):451-62.

5. Xavier MCA, Coradini ALV, Deckmann AC, Franco TT. Lipid production from hemicellulose hydrolysate and acetic acid by Lipomyces starkeyi and the ability of yeast to metabolize inhibitors. Biochem Eng J. 2017:118:11-9.

6. Boulton CA, Ratledge C. Use of transition studies in continuous cultures of Lipomyces starkeyi, an oleaginous yeast, to investigate the physiology of lipid accumulation. Microbiology. 1983;129:2871-6.

7. Calvey $\mathrm{CH}$, Willis LB, Jeffries TW. An optimized transformation protocol for Lipomyces starkeyi. Curr Genet. 2014;60(3):223-30.

8. Oguro Y, Yamazaki H, Shida Y, Ogasawara W, Takagi M, Takaku H. Multicopy integration and expression of heterologous genes in the oleaginous yeast Lipomyces starkeyi. Biosci Biotechnol Biochem. 2015;79(3):512-5. 
9. Dai Z, Deng S, Culley DE, Bruno KS, Magnuson JK. Agrobacterium tumefaciens-mediated transformation of oleaginous yeast Lipomyces species. Appl Microbiol Biot. 2017;101(15):6099-110.

10. Takaku H, Miyajima A, Kazama H, Sato R, Ara S, Matsuzawa T, et al. A novel electroporation procedure for highly efficient transformation of Lipomyces starkeyi. J Microbiol Meth. 2020;169:105816.

11. Dai Z, Pomraning KR, Deng S, Hofstad BA, Panisko EA, Rodriguez D, et al. Deletion of the KU70 homologue facilitates gene targeting in Lipomyces starkeyi strain NRRL Y-11558. Curr Genet. 2019;65(1):269-82.

12. Liu HW, Zhao X, Wang FJ, Jiang XN, Zhang SF, Ye ML, et al. The proteome analysis of oleaginous yeast Lipomyces starkeyi. FEMS Yeast Res. 2011;11(1):42-51.

13. Pomraning KR, Collett JR, Kim J, Panisko EA, Culley DE, Dai ZY, et al. Transcriptomic analysis of the oleaginous yeast Lipomyces starkeyi during lipid accumulation on enzymatically treated corn stover hydrolysate. Biotechnol Biofuels. 2019;12:162.

14. Maruyama Y, Toya Y, Kurokawa H, Fukano Y, Sato A, Umemura H, et al. Characterization of oil-producing yeast Lipomyces starkeyi on glycerol carbon source based on metabolomics and C-13-labeling. Appl Microbiol Biot. 2018;102(20):8909-20.

15. O'Brien EJ, Monk JM, Palsson BO. Using genome-scale models to predict biological capabilities. Cell. 2015;161(5):971-87.

16. Shabestary K, Hudson EP. Computational metabolic engineering strategies for growth-coupled biofuel production by Synechocystis. Metab Eng Commun. 2016:3:216-26.

17. Mendoza SN, Olivier BG, Molenaar D, Teusink B. A systematic assessment of current genome-scale metabolic reconstruction tools. Genome Biol. 2019;20(1):158.

18. Kerkhoven EJ, Pomraning KR, Baker SE, Nielsen J. Regulation of aminoacid metabolism controls flux to lipid accumulation in Yarrowia lipolytica. NPJ Syst Biol Appl. 2016;2:16005

19. Tiukova IA, Prigent S, Nielsen J, Sandgren M, Kerkhoven EJ. Genomescale model of Rhodotorula toruloides metabolism. Biotechnol Bioeng. 2019;116(12):3396-408

20. Pham NTT, Reijnders M, Suarez-Diez M, Nijsse B, Springer J, Eggink G, et al. Genome-scale metabolic modelling underscores the potential of Cutaneotrichosporon oleaginosus ATCC 20509 as a cell factory for biofuel production. Biotechnol Biofuels. 2020;14(1):2.

21. Bommareddy RR, Sabra W, Maheshwari G, Zeng AP. Metabolic network analysis and experimental study of lipid production in Rhodosporidium toruloides grown on single and mixed substrates. Microb Cell Fact. 2015;14:36.

22. Castañeda MT, Nuñez S, Garelli F, Voget C, Battista HD. Comprehensive analysis of a metabolic model for lipid production in Rhodosporidium toruloides. J Biotechnol. 2018;280:11-8.

23. Tang M, Wang YA, Zhou WT, Yang M, Lin Y, Gong ZW. Efficient conversion of chitin-derived carbon sources into microbial lipid by the oleaginous yeast Cutaneotrichosporon oleaginosum. Bioresour Technol. 2020:315:123897.

24. Angerbauer C, Siebenhofer M, Mittelbach M, Guebitz GM. Conversion of sewage sludge into lipids by Lipomyces starkeyi for biodiesel production. Bioresour Technol. 2008;99(8):3051-6.

25. Wild R, Patil S, Popović M, Zappi M, Dufreche S, Bajpai R. Lipids from Lipomyces starkeyi. Food Technol Biotech. 2010;48(3):329-35.

26. Matsakas L, Sterioti A-A, Rova U, Christakopoulos P. Use of dried sweet sorghum for the efficient production of lipids by the yeast Lipomyces starkeyi CBS 1807. Ind Crops Prod. 2014:62:367-72.

27. Spier F, Buffon JG, Burkert CAV. Bioconversion of raw glycerol generated from the synthesis of biodiesel by different oleaginous yeasts: lipid content and fatty acid profile of biomass. Indian J Pathol Microbiol. 2015;55(4):415-22.

28. Calvey CH, Su YK, Willis LB, McGee M, Jeffries TW. Nitrogen limitation, oxygen limitation, and lipid accumulation in Lipomyces starkeyi. Bioresour Technol. 2016:200:780-8.

29. Rahman S, Arbter P, Popovic M, Bajpai R, Subramaniam R. Microbial lipid production from lignocellulosic hydrolyzates: effect of carbohydrate mixtures and acid-hydrolysis byproducts on cell growth and lipid production by Lipomyces starkeyi. J Chem Technol Biotechnol. 2017;92(8):1980-9.

30. Oguri E, Masaki K, Naganuma T, lefuji H. Phylogenetic and biochemical characterization of the oil-producing yeast Lipomyces starkeyi. Antonie Van Leeuwenhoek. 2012;101(2):359-68.
31. Thirumal V, Chistoserdov A, Bajpai R, Bader J, Popovic MK, Subramaniam R. Effect of developed low cost minimal medium on lipid and exopolysaccharide production by Lipomyces starkeyi under repeated fed-batch and continuous cultivation. Chem Biochem Eng Q. 2018;32(4):473-81.

32. Signori L, Ami D, Posteri R, Giuzzi A, Mereghetti P, Porro D, Branduardi P. Assessing an effective feeding strategy to optimize crude glycerol utilization as sustainable carbon source for lipid accumulation in oleaginous yeasts. Microb Cell Fact. 2016;15:75.

33. Ratledge $\mathrm{C}$. The role of malic enzyme as the provider of NADPH in oleaginous microorganisms: a reappraisal and unsolved problems. Biotechnol Lett. 2014;36(8):1557-68.

34. Tang W, Zhang SF, Tan HD, Zhao ZK. Molecular cloning and characterization of a malic enzyme gene from the oleaginous yeast Lipomyces starkeyi. Mol Biotechnol. 2010;45(2):121-8.

35. Papanikolaou S, Aggelis G. Lipids of oleaginous yeasts. Part I: biochemistry of single cell oil production. Eur J Lipid Sci Tech. 2011;113(8):1031-51.

36. Ruan ZH, Hollinshead W, Isaguirre C, Tang YJ, Liao W, Liu Y. Effects of inhibitory compounds in lignocellulosic hydrolysates on Mortierella isabellina growth and carbon utilization. Bioresour Technol. 2015;183:18-24.

37. Zhang Y, Adams IP, Ratledge C. Malic enzyme: the controlling activity for lipid production? Overexpression of malic enzyme in Mucor circinelloides leads to a 2.5-fold increase in lipid accumulation. Microbiology. 2007; 153:2013-25.

38. Li Z, Sun HX, Mo XM, Li XY, Xu B, Tian P. Overexpression of malic enzyme (ME) of Mucor circinelloides improved lipid accumulation in engineered Rhodotorula glutinis. Appl Microbiol Biot. 2013;97(11):4927-36.

39. Anschau A, Xavier MCA, Hernalsteens S, Franco TT. Effect of feeding strategies on lipid production by Lipomyces starkeyi. Bioresour Technol. 2014;157:214-22

40. Gong ZW, Wang Q, Shen HW, Hu CM, Jin GJ, Zhao ZBK. Co-fermentation of cellobiose and xylose by Lipomyces starkeyi for lipid production. Bioresour Technol. 2012;117:20-4.

41. Tapia EV, Anschau A, Coradini ALV, Franco TT, Deckmann AC. Optimization of lipid production by the oleaginous yeast Lipomyces starkeyi by random mutagenesis coupled to cerulenin screening. AMB Express. 2012;2:64.

42. Yang XB, Jin GJ, Gong ZW, Shen HW, Song YH, Bai FW, Zhao ZK. Simultaneous utilization of glucose and mannose from spent yeast cell mass for lipid production by Lipomyces starkeyi. Bioresour Technol. 2014;158:383-7.

43. Nichols NN, Dien BS, Bothast RJ. Use of catabolite repression mutants for fermentation of sugar mixtures to ethanol. Appl Microbiol Biotechnol. 2001;56:120-5.

44. Hua Y, Wang JC, Zhu YL, Zhang B, Kong X, Li WJ, Wang DM, Hong J. Release of glucose repression on xylose utilization in Kluyveromyces marxianus to enhance glucose-xylose co-utilization and xylitol production from corncob hydrolysate. Microb Cell Fact. 2019;18:1-18.

45. Kim SB, Kwon DH, Park JB, Ha SJ. Alleviation of catabolite repression in Kluyveromyces marxianus: the thermotolerant SBK1 mutant simultaneously coferments glucose and xylose. Biotechnol Biofuels. 2019:12:90.

46. Kastner JR, Jones WJ, Roberts RS. Simultaneous utilization of glucose and D-xylose by Candida shehatae in a chemostat. J Ind Microbiol Biotechnol. 1998;20:339-43.

47. Masri MA, Garbe D, Mehlmer N, BrückTB. A sustainable, high-performance process for the economic production of waste-free microbial oils that can replace plant-based equivalents. Energ Environ Sci. 2019;12(9):2717-32

48. Gong ZW, Zhou WT, Shen HW, Yang ZH, Wang GH, Zuo ZY, et al. Cofermentation of acetate and sugars facilitating microbial lipid production on acetate-rich biomass hydrolysates. Bioresour Technol. 2016;207:102-8.

49. Lim HG, Lee $J H$, Noh MH, Jung GY. Rediscovering acetate metabolism: its potential sources and utilization for biobased transformation into valueadded chemicals. J Agric Food Chem. 2018;66(16):3998-4006.

50. Dellomonaco C, Clomburg JM, Miller EN, Gonzalez R. Engineered reversal of the $\beta$-oxidation cycle for the synthesis of fuels and chemicals. Nature. 2011;476(7360):355-9.

51. Sheppard MJ, Kunjapur AM, Prather KLJ. Modular and selective biosynthesis of gasoline-range alkanes. Metab Eng. 2016;33:28-40.

52. Wu JJ, Zhang X, Xia XD, Dong MS. A systematic optimization of medium chain fatty acid biosynthesis via the reverse beta-oxidation cycle in Escherichia coli. Metab Eng. 2017:41:115-24. 
53. Lian JZ, Zhao HM. Reversal of the $\beta$-oxidation cycle in Saccharomyces cerevisiae for production of fuels and chemicals. ACS Synth Biol. 2015;4(3):332-41.

54. Riley R, Haridas S, Wolfe KH, Lopes MR, Hittinger CT, Göker M, et al. Comparative genomics of biotechnologically important yeasts. Proc Natl Acad Sci USA. 2016;113(35):9882-7.

55. Gombert AK, Moreira dos Santos M, Christensen B, Nielsen J. Network identification and flux quantification in the central metabolism of Saccharomyces cerevisiae under different conditions of glucose repression. J Bacteriol. 2001;183(4):1441-51.

56. Förster J, Gombert AK, Nielsen J. A functional genomics approach using metabolomics and in silico pathway analysis. Biotechnol Bioeng. 2002:79(7):703-12.
57. Anschau A, Franco TT. Cell mass energetic yields of fed-batch culture by Lipomyces starkeyi. Bioprocess Biosyst Eng. 2015;38:1517-25.

58. von Kamp A, Thiele S, Häedicke O, Klamt S. Use of Cell NetAnalyzer in biotechnology and metabolic engineering. J Biotechnol. 2017;261:221-8.

\section{Publisher's Note}

Springer Nature remains neutral with regard to jurisdictional claims in published maps and institutional affiliations.
Ready to submit your research? Choose BMC and benefit from:

- fast, convenient online submission

- thorough peer review by experienced researchers in your field

- rapid publication on acceptance

- support for research data, including large and complex data types

- gold Open Access which fosters wider collaboration and increased citations

- maximum visibility for your research: over 100M website views per year

At BMC, research is always in progress.

Learn more biomedcentral.com/submissions 